\title{
Hemisphere and ear asymmetry in the auditory evoked response to musical chord stimuli
}

\author{
JOHN M. TAUB, PETER E. TANGUAY, CATHERINE N. DOUBLEDAY, DOUGLAS CLARKSON \\ University of California, Los Angeles, Los Angeles, California 90024
}

and

ROGER REMINGTON

University of Oregon, Eugene, Oregon 97403

\begin{abstract}
The human averaged auditory evoked response (AER) to monaurally presented musical chord stimuli was recorded simultaneously from electrodes placed symmetrically over the two cerebral hemispheres at central and Wernicke (W) scalp locations. Stimulus presentation was quasi-random to the left (L) and right $(\mathrm{R})$ ears of 14 normal-hearing right-handed male university students. The mean integrated amplitude over the initial 300 msec of the AER reflected asymmetries at the W locations as a function of hemisphere derivation and ear stimulated. The major interhemispheric difference observed when effects of contralateral auditory pathway-to-cortex projections had been equated was a significantly greater magnitude integrated amplitude response at the right $\left(\mathrm{W}_{2}\right)$ scalp site to L-ear stimulation in comparison with the AER at the left $\left(\mathrm{W}_{1}\right)$ cortical location to R-ear stimulation. Differences of AERs between hemispheres summed across both ears stimulated conceived as attributable to additive auditory input showed a significantly greater integrated amplitude value at $\mathrm{W}_{2}$. When effects of contralateral auditory pathway predominance were examined, the AER integrated amplitude from $\mathrm{W}_{2}$ exceeded the hemisphere response at $\mathrm{W}_{1}$ to L-ear stimulation. The demonstrated asymmetries in the evoked response to musical chords may be associated with preponderance of the right hemisphere and saliency of the L ear for nonverbal, nonmeaningful auditory stimuli.
\end{abstract}

A comparatively recent development in human neurophysiology has been the application of electroencephalographic (EEG) techniques in attempting to elucidate functional differences between the left and right cerebral hemispheres (see. for examples. Callaway d Harris, 1974; Davis \& Wada. 1974: Doyle, Ornstein. \& Galin. 1974). Among the lirst of such investigations on lateralized brain functions was that by McAdam and Whittaker (1971). Maximal, slow negative potentials were generated over the left, presumably speech-dominant, hemisphere when subjects spoke meaningful polysyllabic words. While electrical activity was bilaterally symmetrical when nonverbal utterances were vocalized.

Support for this research was provided by the Grant Foundation. by U.S. Public Health Service Research Scientist Development Award MH47361 to Dr. Tanguay, by a postdoctoral traineeship to John Taub through UCLA Brain Research Institute National Institute of Mental Health Interdisciplinary Training Grant MH(06415, and by U.S. Public Health Service Grant MH26047. I wish to thank Dr. Don Dirks, and Dr. Don Morgan of the UCLA Audiology Laboratory, for their generous advice and assistance with the psychoacoustic and other aspects of this study, and Dr. Howard B. Ruhm, for his encouragement and germinal suggestions. Address correspondence and reprint requests to John M. Taub. $\mathrm{PhD}$. Sleep and Dream Laboratory, University of Virginia School of Medicine. Department of Psychiatry. Charlottesville. Virginia $22 \times() 1$.
Left-right ass mmetries of varying degrees have been reported for human scalp-recorded responses to speceh and nonverbal stimuli. Morrell and Salamy (14-1) observed a larger deflection of the $N_{1}$ evoked potcutial component over the left than over the right temporo-parietal cortical area to nonsense words. Larger amplitudes and more prominent waveform components of averaged evoked responses at the left hemisphere for linguistic compared to nonlinguistic tasks hal: also been reported in both the visual (Buchsbatum \& Fedio, 1969) and auditory (Friedman. Simson. Ritter. \& Rapin, 1975; Wood, 1975) modalities. Buchsbaum and Fedio (1969) reported that shorter left occipital $\left(O_{1}\right)$ latency responses occurred to tachistoscopic presentation of three-letter words than for similarly arrayed dot designs. Wood $\left(14^{-5}\right.$ observed eroked potential differences for time pribits along the waveform of the response at corresponding locations over the left hemisphere $\left(C_{3}\right.$ and $\mathrm{I}_{3}$ ). depending upon whether subjects were required to discriminate either auditory or phonetic dimensions among identical consonant-vowel syllables. Larger eroked potentials recorded from left than from right temporo-parietal electrodes were reported by Friedman et al. (1975) in a vigilance condition for the $\mathrm{N}_{1}$ component to words defined as signals and for the P300 amplitude to nonspeech human-generated vocalizations designated to be 
nonsignal stimuli. Matsumiya, Tagliasco, Lombroso. and Goodglass (1972) reported hemispheric asymmetry of the auditory evoked response (AER) to monosyllabic words. mechanical noises, and sentences. The observed left $\left(\mathrm{W}_{1}-\mathrm{P}_{3}\right)$ greater than right hemispheric $\left(\mathrm{W}_{2}-\mathrm{P}_{2}\right)$ asymmetry was ascribed to the significance of the auditory stimulus for the subject rather than whether it was verbal or nonverbal. What has generally emerged from recent studies on scalp-recorded potentials is increased cortical activation of the left hemisphere to phonemes. word fragments, nonsense words, entire sentences, human vocalizations such as tongue snaps, coughing. "histling. etc.. and even contextual meaning (Brown. Marsh, \& Smith, 1973; Teyler, Roemer. Harrison, \& Thompson. 1973).

Although not as extensively demonstrated, right hemispheric asymmetry in electrocortical evoked activity has also been reported for simple unstructured nonverbal stimuli in the auditory modality (Cohn, 1971; Peronnet. Michel. Echallier, \& Girod, 1974; Ruhm, 1971). Evoked responses to "loud" binaurally presented click stimuli were reported by Cohn (1971) to exhibit an amplitude of cortical output with a $14-\mathrm{msec}$ latency that was greater at the right acoustic meatus. Attention was given to the possibility of asymmetric microreflexes as an extracerebral origin for the right-hemisphere response in commentaries upon Cohn's (1971) tindings (Bickford, 1971, p. 129; Matsumiya et al., 1972: Wood. Goff, \& Day, 1971).

Almost without exception. the approach taken in eroked potential investigations of audition has been binaural stimulation. Ruhm (1971) studied clickevoked cortical responses during monaural stimulation, and among his findings were that, when the left (L) ear was stimulated compared to the right $(R)$, the $\mathrm{N}_{1}-\mathrm{P}_{2}$ amplitude component was approximately $50 \%$ larger over the right temporal cortex $\left(\mathrm{T}_{4}\right)$ than at the left $\left(\mathrm{T}_{3}\right)$. Correspondingly, Peronnet et al. (1974) stimulated the $\mathrm{L}$ and $\mathrm{R}$ ears in separate sessions, but with $1-\mathrm{kHz}$ tones. and reported larger "peak amplitudes" of the right hemisphere $\left(T_{4}\right)$ response than of the left $\left(T_{3}\right)$. Possibly, since so few studies have adopted the strategy of monaural stimulus presentation. AER asymmetries are seldom conceived as emanating from an interaction between ear and hemisphere effects.

One effect not specifically studied, as such, is that of the difference between the L-ear/right-hemisphere and R-ear left-hemisphere contralateral auditory pathway-to-cortex projections which might be reflected in averaged scalp-recorded responses evoked by specific nonlinguistic stimuli. The objective of the present experiment. then, was to study various asymmetries in averaged evoked potentials over both cerebral hemispheres with musical chords as the stimuli presented in quasi-random sequence to the $\mathrm{L}$ and $\mathrm{R}$ ears. In accordance with a previous finding (Ruhm, 1971) was the prediction that averaged cortical potentials elicited by musical chords would. as for clicks, be exceeded in amplitude over the right side of the scalp than at the left for stimuli presented to the contralateral $(\mathrm{L})$ ear.

\section{METHOD}

\section{Subjects}

Fourteen male subjects were selected from respondents to an inventory distributed among university students. The screening device was a modified version of the Cornell Medical Health Index (Brodman, Erdmann, \& Wolff, 1956), which contained questions about medical and psychosomatic conditions and sleep characteristics. Subjects were considered for study only if their responses to the inventory were not indicative of sleep disturbance, medical problems. psychiatric disorders, and frequent alcohol or drug usage. None of them had previously received any extensive musical training, and all were right-handed as determined by stand ard questionnaire criteria (Annett, 1967). The mean age of the subjects was 22.7 years, and the ages ranged from 18 to 24 years.

A screening audiogram showed the subjects' hearing to be normal. The audiogram was based upon their detection in each ear of frequencies from $250 \mathrm{~Hz}$ to $8 \mathrm{kHz}$ at $10 \mathrm{~dB}$ (reference: .002 dynes $/ \mathrm{cm}^{2}$ ) using a Beltone audiometer.

\section{Stimuli}

Stimuli were computer-generated musical chords which had been recorded on a Sony Model TC-270 stereo tape recorder. They were played back to the subjects monaurally through headphones at approximately $60-\mathrm{dB}$ intensity, measured by a Bruel and Kjaer sound pressure level meter. The stimuli comprised a major. a minor, and a diminished chord produced by a music synthesis interpreter (Matthews. 1969). Each of these three notes was composed of three harmonics. All stimuli were edited with a PDP-12 computer to be identical in rise time $(3 \mathrm{msec})$, initial fundamental frequency $(100 \mathrm{~Hz})$, duration $(300 \mathrm{msec})$, decay time $(7 \mathrm{msec})$, and intensity. The recorded chords were dubbed 50 times in quasi-random order at intervals of 1 per $4 \mathrm{sec}$.

\section{Electrophysiological Recording}

Scalp recordings were made using $\mathrm{Ag} / \mathrm{AgCl}$ disk electrodes placed at left and right central locations $\left(C_{3}\right.$ and $\left.C_{4}\right)$ according to the International 10-20 system (Jasper. 1958) and left and right Wernicke (W) sites (midway between $\mathrm{T}_{5}$ and $\mathrm{C}_{3}$ and midway between $T_{6}$ and $C_{4}$ over auditory cortex, and labeled $W_{1}$ and $W_{2}$. respectively). The $\mathrm{W}$ placements were chosen because of their proximity to cortical locations for which hemispheric asymmetries in the AER had been previously reported (Matsumiya et al.. 1972; Morrell \& Salamy. 1971). The reference electrodes were placed on ipsilateral earlobes. and a ground on the forehead. EOG was recorded from electrodes located at the lateral canthi of each eye and linked together. Interelectrode resistance was maintained below $10 \mathrm{k} \Omega$.

EEG and EOG activity were amplified using a Grass Model III electroencephalograph with half-amplitude bandwidths of $0.5-3 \mathrm{kHz}$ and a 0.3 -sec time constant. The EEG. EOG, a 50- $\mathrm{V} \mathrm{V}$ calibration signal. and two Schmitt trigger pulses representing the onset of R-or L-ear stimulation were recorded simultaneously on a Vetter Model A FM instrument tape recorder with band-pass limits from dc to $300 \mathrm{~Hz}$.

\section{Procedure}

All subjects reported to the laboratory at approximately 10:00 a.m. following a typical night of sleep at home. The time of day for recording was kept constant. since diurnal changes in several evoked-response characteristics have been reported 
(Heninger. McDonald, Gott. \& Sollberger, 1969). Duration of the experiment was approximately $90 \mathrm{~min}$. including preparation and attachment of scalp electrodes. prior to which the subject's hearing was ascertained on a screening audiogram.

The subjects were told that the purpose of the investigation was to study the relationship between auditory perception and patterns of bioelectric cortical activity. The subject was seated in a reclining chair in a diffusely illuminated sound-attenuated room, and his posture was adjusted so that little or no muscle activity was discernible in ongoing EEG activity. The subject was instructed to keep his cyes closed. but to remain alert and to attend to the sound stimuli. The EEG was monitored to ensure maintenance of a wakeful state.

The experimental session comprised presentation of an audio tape containing 150 stimuli. During the experiment. 75 stimuli were delivered separatels to the $L$ and $R$ ears in quasi-random order. Of these 75 stimuli. 25 were a major, 25 a minor, and 25 a diminished chord. The position of the headphones was reversed for alternate subjects. Presumably. any alteration in the subjects level of attention or psychophysiological state would have influenced responses evoked by the stimuli similarly, since each stimulus was presented in quasi-randon sequence to the $\mathbf{L}$ and $\mathbf{R}$ ears. and simultaneous recordings were obtained from locations overlying both cerebral hemispheres (cf. Bess \& Ruhm, 1972). Following a previously adopted procedure (Cohn. 1971), a 10-min control period was imposed after the experimental session during which similar conditions were maintained, except that the subject's headphones were disconnected from the stereo while the ongoing EEG along with 150 stimulus markers were recorded on FM magnetic tape.

\section{Data Processing}

Data analysis was conducted off-line using a PDP-12 computer programmed to sample 500 data points within a 1 -sec interval following stimulus onset. AERs comprising 70 individual stimuli were computed for $C_{3}, C_{4}, W_{1}, W_{2}$, and EOG. Three evoked potentials were produced per channel, representing $\mathrm{L}$-ear stimulation. R-ear stimulation, and the no-stimulus control condition. Data were stored on magnetic tape for off-line processing.

Each AER was recalled from magnetic tape, coded to allow a blind scoring procedure. and displayed on a cathode-ray oscilloscope interfaced with the computer. The $P_{1}-N_{1}-P_{2}$ components were visually identified in the response. latencies were measured in milliseconds. and amplitudes $\left(P_{1}-N_{1}, N_{1}-P_{2}\right)$ were computed in microvolts. The computer then calculated and displayed the mean amplitude of the first $300 \mathrm{msec}$ of the AER that was used as a baseline estimate in deriving the integrated amplitude. The computer was then programmed to rectify and integrate that segment of the AER which extended from $P_{1}$ to that point at which the negative evoked potential component subsequent to $P_{2}$ intersected the baseline. An integrated amplitude value as derived divided by the data points included within $P_{2}-N_{1}-P_{2}$ baseline limits was then printed numerically. All amplitude values were normalized using the previously recorded $50-\mu \mathrm{V}$ calibration signal.

\section{Statistical Analysis}

Eight AERs were obtained per subject comprising two sets of four recorded from $C_{3}, C_{4}, W_{1}$, and $W_{2}$, each set representing the electrocortical responses to $\mathrm{L}$ - or $\mathrm{R}$-ear stimulation. As in previous studies which adopted a paradigm of monaural stimulus presentation and nonverbal stimuli (Peronnet et al., 1974; Ruhm. $1971)$. amplitude measures $\left(N_{1}-P_{2}\right.$ and $\left.P_{1}-N_{1}-P_{2}\right)$ were used as indicants of AER asymmetries. The evoked potential amplitude values of hemispheric responses as a function of $L$ - and $R$-ear stimulation were evaluated by $t$ tests for correlated pairs of means supplemented by the sign test (Siegel, 1956, pp. 68-75) to determine the signiticance of the number of subjects showing either left greater than right or right greater than left hemisphere amplitudes.
EAR STIMULATED

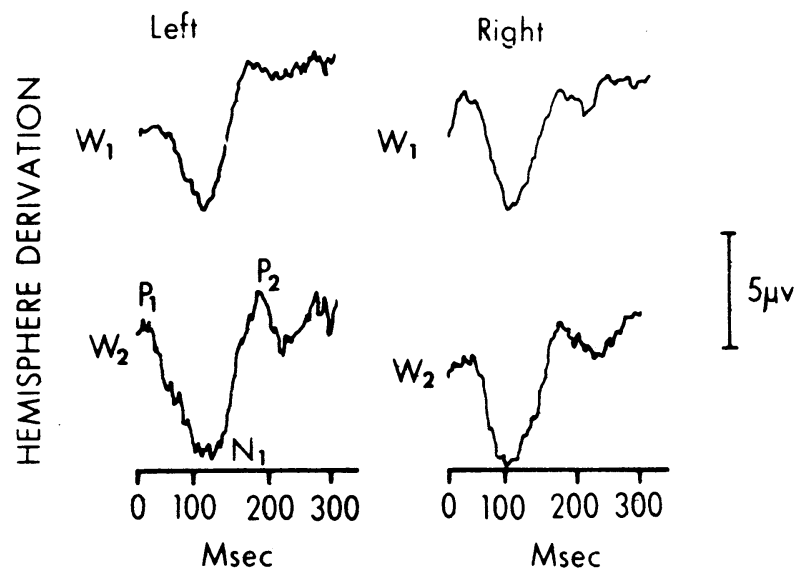

Figure 1. Averaged evoked responses recorded in a normal male adult from Wernicke $(W)$ scalp areas over the left $\left(W_{1}\right)$ and right $\left(W_{2}\right)$ hemisphere to musical chord stimuli presented to the left and right ears. Lower left response indicates the $P_{1}, N_{1}$, and $P_{2}$ components. First 300 msec of response. Calibration: $5 \mu \mathrm{V}$.

\section{RESULTS}

Figure 1 show's the averaged evoked activity from one subject at $W_{1}$ and $W_{2}$ derivations to $L$ - and $R$-ear stimulation with individual waveform components labeled. Electrocortical responses to musical chord stimuli were almost invariably composed of two positive peaks $\left(P_{1}\right.$ and $\left.P_{2}\right)$ separated by a deep negative peak $\left(\mathrm{N}_{1}\right)$.

Across scalp sites, AER latency peaks in order of occurrence after stimulus onset (Table 1) ranged from 41 to $50 \mathrm{msec}\left(\mathrm{P}_{1}\right)$. from 104 to $122 \mathrm{msec}\left(\mathrm{N}_{1}\right)$, and from 213 to $245 \mathrm{msec}\left(\mathrm{P}_{2}\right)$. Owing to large within- and between-subject variance. peak latencies showed no systematic effects in relationship to L- and R-ear stimulation over the four cortical areas.

The mean values of the AER at the Wernicke and central scalp locations for the integrated $\left(\mathrm{P}_{1}-\mathrm{N}_{1}-\mathrm{P}_{2}\right)$

Table 1

AER Latency Components (Milliseconds) as a Function of Scalp Location and Ear Stimulated

\begin{tabular}{clrrrr}
\hline $\begin{array}{c}\text { AER } \\
\text { Measure- } \\
\text { ment }\end{array}$ & $\begin{array}{l}\text { Ear } \\
\text { Stimu- } \\
\text { lated }\end{array}$ & \multicolumn{1}{c}{$\mathrm{W}_{2}$} & \multicolumn{1}{c}{$\mathrm{W}_{1}$} & \multicolumn{1}{c}{$\mathrm{C}_{4}$} & \multicolumn{1}{c}{$\mathrm{C}_{3}$} \\
\hline \multirow{2}{*}{$\mathrm{P}_{1}$} & Left & 56.28 & 51.14 & 44.28 & 41.00 \\
& Right & 56.14 & 41.42 & 49.86 & 44.14 \\
$\mathrm{~N}_{1}$ & Left & 114.14 & 118.58 & 103.00 & 102.00 \\
& Right & 122.86 & 109.28 & 104.28 & 104.72 \\
$\mathrm{P}_{2}$ & Left & 238.80 & 225.14 & 218.66 & 255.42 \\
& Right & 235.08 & 225.60 & 228.30 & 213.28 \\
\hline
\end{tabular}


and peak-to-peak component amplitudes $\left(\mathrm{N}_{1}-\mathrm{P}_{2}\right.$, $\left.\mathrm{P}_{1}-\mathrm{N}_{1}\right)$ are presented in Table 2. Electrode location, as previously reported (e.g.. Morrell \& Salamy, 1971), was a significant factor for interhemispheric differences. Consistent asymmetries were observed in the integrated and $\mathrm{N}_{1}-\mathrm{P}_{2}$ AER measures, but not in the amplitude of $P_{1}-N_{1}$. These electrophysiological asimmetries occurred at the Wernicke leads as a function of which ear had been stimulated and the specitic hemisphere recorded from. In contrast, no systematic hemispheric differences were present at the central (Rolandic) locations, although the largest amplitudes were recorded from Rolandic sites (Table 2).

Tests of statistical signiticance were applied only to the integrated and $\mathrm{N}_{1}-\mathrm{P}_{2}$ AER amplitude measures obtained from the $\mathrm{W}$ electrode derivations. Four main sets of comparisons were performed as follows: (1) $\mathrm{W}_{2}$ with $W_{1}$ to $L$-ear stimulation and (2) to R-ear stimulation as tests for the predicted predominance of contralateral acoustic periphery-neurological projections into the cerebral hemispheres; (3) $\mathrm{W}_{2}$ to L-ear stimulation with $\mathrm{W}_{1}$ to $\mathrm{R}$-ear stimulation to test for interhemispheric differences when contralateral ear-cortex projections were equated; (4) $\mathrm{W}_{2}$ with $\mathrm{W}_{1}$ summed across both ears stimulated to examine the additive effect of $L$ and $R$ auditory input.

Table 2

Interhemispheric Differences in AER Amplitude as a Function of Scalp Location and Ear Stimulated

\begin{tabular}{|c|c|c|c|c|c|}
\hline $\begin{array}{l}\text { AER } \\
\text { Measure- } \\
\text { ment }\end{array}$ & $\begin{array}{c}\text { Ear } \\
\text { Stimulated }\end{array}$ & $\mathrm{W}_{2}$ & $\mathrm{~W}_{1}$ & $\mathrm{C}_{4}$ & $\mathrm{C}_{3}$ \\
\hline \multirow{3}{*}{$\begin{array}{l}\mathrm{P}_{1}-\mathrm{N}_{1}-\mathrm{P}_{2} \\
\text { Integrated } \\
\text { amplitude } \\
\text { (mean inte- } \\
\text { gration } \\
\text { units) }\end{array}$} & \multicolumn{5}{|c|}{$\begin{array}{c}t=1.77^{*} \\
p \leqslant .05\end{array}$} \\
\hline & Left & \multicolumn{2}{|c|}{$.66+\longleftrightarrow .56$} & .99 & .96 \\
\hline & Right & .65 & .51 & 1.02 & .93 \\
\hline \multirow{2}{*}{$\begin{array}{l}\mathrm{N}_{1}-\mathrm{P}_{2} \\
(\text { Mean } \mu \mathrm{V})\end{array}$} & Left & \multicolumn{2}{|c|}{ 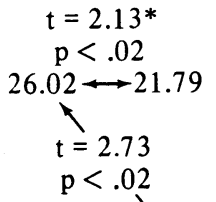 } & 38.79 & 36.77 \\
\hline & Right & 23.91 & 20.21 & 38.01 & 35.03 \\
\hline $\begin{array}{l}P_{1}-N_{1} \\
(\text { Mean } \mu \mathrm{V})\end{array}$ & $\begin{array}{l}\text { Left } \\
\text { Right }\end{array}$ & $\begin{array}{l}15.13 \\
15.59 \\
\end{array}$ & $\begin{array}{l}15.49 \\
14.60 \\
\end{array}$ & $\begin{array}{l}25.22 \\
26.54\end{array}$ & $\begin{array}{l}25.93 \\
26.37 \\
\end{array}$ \\
\hline
\end{tabular}

Note-The $t$ tests were based upon $13 \mathrm{df}$ and two-tailed except as indicated.

*One-tailed probability level.

†For AERs summed across both ears stimulated, $W_{2}>W_{1}, t=$ $2.40, p<.05$.
Table 3

Direction of AER Hemispheric Asymmetries Exhibited by Subjects

\begin{tabular}{|c|c|c|c|c|}
\hline $\begin{array}{l}\text { AER } \\
\text { Measure- } \\
\text { ment }\end{array}$ & $\begin{array}{c}\text { Ear Stimulation- } \\
\text { Hemisphere } \\
\text { Comparisons }\end{array}$ & $\mathrm{W}_{2}>\mathrm{W}_{1}$ & $\mathrm{~W}_{1}>\mathrm{W}_{2}$ & $\begin{array}{l}\text { Signifi- } \\
\text { cance } \\
\text { Level }\end{array}$ \\
\hline \multirow[t]{2}{*}{$\begin{array}{l}P_{1}-N_{1}-P_{2} \\
\text { Integrated }\end{array}$} & \multirow{2}{*}{$\begin{array}{l}\text { Left ear- } W_{2} \text { with } \\
\text { Right ear- } W_{1} \\
\text { Right ear: } W_{1} \text { with } W_{2} \\
\text { Left ear: } W_{1} \text { with } W_{2}\end{array}$} & 12 & 2 & $<.006$ \\
\hline & & $\begin{array}{r}11 \\
8\end{array}$ & $\begin{array}{l}3 \\
6\end{array}$ & $\begin{array}{c}<.029 \\
\text { n.s. }\end{array}$ \\
\hline \multirow[t]{2}{*}{$\begin{array}{l}\mathrm{N}_{1}-\mathrm{P}_{2} \\
\text { Amplitude }\end{array}$} & \multirow{2}{*}{$\begin{array}{l}\text { Left ear- } W_{2} \text { with } \\
\text { Right ear- } W_{1} \\
\text { Right ear: } W_{1} \text { with } W_{2} \\
\text { Left ear: } W_{1} \text { with } W_{2}\end{array}$} & 11 & 3 & $<.029$ \\
\hline & & $\begin{array}{r}10 \\
8\end{array}$ & $\begin{array}{l}4 \\
6\end{array}$ & $\begin{array}{l}\text { n.s. } \\
\text { n.s. }\end{array}$ \\
\hline
\end{tabular}

*Sign test

\section{Group Results}

The AER asymmetry of greatest magnitude was in comparison of $W_{2}-\mathrm{L}$ ear stimulation with $\mathrm{W}_{1}-\mathrm{R}$ ear stimulation (Table 2). The evoked response at $\mathrm{W}_{2}$ was significantly larger for both the integrated $P_{1}-N_{1}-P_{2}$ $(p<.01)$ and $N_{1}-P_{2}(p<.02)$ amplitude measures. Interhemispheric differences assessed by AERs summed across the $\mathrm{L}$ and $\mathrm{R}$ ears (cf. Ratliffe \& Greenberg. 1972) indicated that the integrated amplitude recorded over $\mathrm{W}_{2}$ was significantly larger $(p)<.05)$ than at $W_{1}$, an effect present in 10 of 14 subjects.

To L-ear stimulation only, signiticant asymmetries between $W_{1}$ and $W_{2}$ were detected in the two amplitude parameters. In the predicted direction, the right hemisphere $\mathrm{N}_{1}-\mathrm{P}_{2}$ and $\mathrm{P}_{1}-\mathrm{N}_{1}-\mathrm{P}_{2}$ response amplitudes were then greater ( $\mathrm{ps} \leqslant .05$, one-tailed tests) than the left. With eight t tests computed, the probability is $\mathrm{p}<.001$ that the tive which attained statistical significance occurred by chance (Sakoda, Cohen. \& Beall. 1954).

\section{Individual Results}

Table 3 illustrates the number of subjects in whom interhemispheric AER differences were exhibited. As might be predicted from the group results, asymmetry was most reliably observed in the comparison between $\mathrm{W}_{2}$ - $\mathrm{L}$ ear stimulation with $\mathrm{W}_{1}-\mathrm{R}$ ear stimulation. The consistency of this effect was demonstrated in that eroked potential amplitudes at the right hemisphere derivation were significantly larger for the $P_{1}-N_{1}-P_{2}$ measure in 12 subjects $(\mathrm{p}<.006)$ and for the $\mathrm{N}_{1}-\mathrm{P}_{2}$ component in 11 of them $(p<.029)$.

The one other statistically significant result reflected by this analysis was that when stimulation was to the $R$ ear. $P_{1}-N_{1}-P_{2}$ magnitudes in 11 of the 14 subjects $(p<.029)$ were larger at $W_{2}$ compared with $W_{1}$. In contrast, however, to group statistics, no 
significance could be found in either of the AER amplitude measures between $W_{1}$ and $W_{2}$ to $L$-ear stimulation (Table 3).

Identifiable evoked potential waveforms were not observed during the control condition. In the on-line monitored EOG channel, oculomotor activity could be discerned but was infrequent and randomly distributed with respect to stimulus onset. Low-voltage 2-7-Hz/sec Stage 1 sleep (Rechtschaffen \& Kales. 1968) did not occur in any great degree or with any regularity.

\section{DISCUSSION}

The presence of specialized neurological substrates for audition within each hemisphere has been proposed (Milner, 1962, pp. 177-195) and an anatomical asymmetry between an area for speech in the left hemisphere and a corresponding region in the right has been reported (Geschwind, 1972; Geschwind \& Levitsky, 1968). Possibly indicating differentially lateralized brain functions, it appears from the present results that the averaged EEG response amplitude evoked by nonverbal sounds such as musical chords is detectably larger at the right than over the left auditory cortex.

Any conclusions or extrapolations concerning specific effects on the AER resulting from musical chords per se are inevitably limited, since such sounds represent merely a sample from the large population of discrete nonverbal, nonmeaningful stimuli. Therefore, relationships between synthetic music as applied in the present study and asymmetry of scalp-recorded brain activity can only be tentatively inferred until other acoustic signals are compared within the same experimental paradigm. For example. besides L-ear/right-hemisphere AER laterality to musical chords, as we observed, there is recent evidence that certain speech stimuli can produce comparable results (Haaland, 1974).

The most distinctive and reliable interhemispheric difference in the AER was achieved in the comparison between $W_{2}-\mathrm{L}$ ear stimulation and $W_{1}-R$ ear stimulation. Assumed in performing this comparison was that brain correlates of asymmetries to the musical chord stimuli would be observable when stimulus presentation to the direct contralateral auditory pathways projecting into the hemispheres was equated. In support of the assumption, values of two evoked potential amplitude measures were larger over the right hemisphere, reached group statistical significance, and for both a statistically significant majority of subjects exhibited asymmetry in the same direction.

Other aspects of the findings attained statistical significance in either group or individual data only, and were thus less consistent than the above. As predicted, and confirming previous evoked potential studies in which clicks (Ruhm, 1971) or tones (Peronnet et al., 1974) were presented monaurally, was the right greater than left AER magnitude to L-ear stimulation when mean amplitudes of the group were considered. Possibly, then, the right cerebral hemisphere predominates for many mechanically produced nonverbal stimuli, among which can be included computer-generated music, and this effect, as indicated by the AER, becomes potentiated when the contralateral (L) ear is stimulated. In response to $\mathrm{R}$-ear signal presentation, lesser evidence for an interhemispheric evoked response difference across AER measures could be explained as an antagonism of two factors: (1) contralateral auditory pathway saliency (favoring the left hemisphere AER) vs. (2) the ipsilateral (right), but less salient, neurological acoustic projection into the presumably preferential (for the stimulus in question) right hemisphere. The single signiticant finding of a larger right- than left-hemisphere integrated amplitude response to $\mathrm{R}$-ear stimulation in 11 subjects concurs with such an interpretation.

The integrated amplitude being larger at $\mathrm{W}_{2}$ when AERs were summed across the $L$ and $R$ ears can perhaps be conceived as an analogue to binaural stimulation. Considered as an additive effect on the AER, stimulation of both ears could be interpreted to represent both a predominance of the left contralateral auditory pathway and a right hemisphere preponderance for musical chords or other such sounds with similar physical properties.

The basic information which detected various interhemispheric differences in the group results was conveyed by the electrical activity over the most prominent portion of the evoked response-the mean integrated amplitude or $\mathrm{P}_{1}-\mathrm{N}_{1}-\mathrm{P}_{2}$ complex. The possibility therefore appears reasonably raised, as did Wood (1975), and concurs with previous findings (e.g., Wood, 1975; Wood et al., 1971), that asymmetries need not be directly related to a particular evoked potential component as conventionally classified (Davis, Mast, Yoshie, \& Zerlin, 1966).

\section{Hemispheric Specialization}

Although conceptualized from a neurological perspective, hemispheric specialization remains a hypothetical construct only vaguely defined in terms of CNS substrata, and its hypothetical relationship to the present findings cannot be assessed with complete certitude. The results do, however, concur with previously reported evidence from neuropsychological and EEG studies on lateralized brain functions.

Thus, augmented suppression of the EEG alpha rhythm recorded from the right hemisphere was observed when subjects performed nonlinguisticmusical tasks (Doyle et al., 1974; McKee, Humphrey, \& McAdam, 1973), such as detecting a particular 
theme while listening to a Bach concerto. On another level of observation, the present psychophysiological experiment gives some corroboration to the conclusion drawn from an initial observation by Kimura (1964), using the dichotic listening technique, that melodies were recognized better from the $\mathrm{L}$ ear and processed in the right hemisphere.

Asymmetry in the AER parallels the finding of another dichotic listening study which showed that musical chords were more accurately perceived when presented to the $\mathrm{L}$ ear than to the $\mathrm{R}$ ear (Gordon, 1970). Further evidence converging with the present findings was the recent demonstration that, even without recourse to interaural competition. musically naive listeners recognized melodic information better with the $\mathrm{L}$ ear under conditions of monaural stimulation (Bever \& Chiarello, 1974).

Accepting the common assumption that neurological connections projecting from the contralateral (left) auditory pathway into the right cerebral hemisphere predominate for a vast majority of nonverbal sounds (Kimura, 1967), it is not implausible to postulate that selective neural events occurred in the right side of the brain to musical chords. The averaged evoked potential, if taken as an indicant of lateralized brain functions, is probably produced by intermittent synchronization of neuronal populations (Elul. 1972) which may be more readily available for activation in the right auditory cortex when elicited by nonlinguistic, nonmeaningful stimuli. Interpretation of the present results in terms of hemispheric specialization, as indicated by AER laterality to such nonverbal sound stimuli which are musical in nature, is favored, but alternative explanations are also conceivable and must therefore be considered.

Among the processes recently hypothesized as being mediated differentially by the cerebral hemispheres, Broadbent (1974, pp. 31-41) considered categorization of changes in the environment, which is quite tenable for explaining AER asymmetries to alternate L-R ear stimulation. Conceivably, then, the observed AER interhemispheric differences might not be exclusively associated with stimulus structure, but partially the result of aural laterality, since presentation to the ears was random. The random pattern of auditory stimulation could certainly be conceived as a series of transitions in the acoustic environment and responded to as such by feature-sensitive neurons in either hemisphere asymmetrically.

\section{Stimulus Parameters}

Sensitivity to intensity and location of a sound source in space are shown by cortical neurons in the cat (Brugge, Dubrowsky, Aitkin, \& Anderson, 1969; Evans, 1968, pp. 272-287; Hall \& Goldstein, 1968). If such findings can be extrapolated to psychoacoustic studies of dual functional specialization in the normal intact human brain (Kimura, 1973), the asymmetries observed in the AER might only be specific to the stimulus intensity (cf. Davis \& Wada, 1974) and the interstimulus interval (cf. Ruhm, 1971) under conditions of this experiment.

\section{Subject Variables}

That the subjects' attentiveness affected the observed AER interhemispheric asymmetries appears unlikely since laterality of AER amplitude to nonverbal stimuli presented monaurally every $4 \mathrm{sec}$ to the $L$ and $R$ ears was shown by Ruhm (1971) under somewhat similar experimental conditions as being unrelated to state of attention. It also seems unlikely that results would have differed with respect to subject variability of AER parameters if the total number of responses averaged were to have been increased. Increased accumulations during the averaging procedure do not always reduce within-subject variance of the AER (Keating \& Ruhm, 1971).

In summary, various asymmetries were indicated in the AER to monaural musical chord stimuli. Right greater than left hemisphere amplitude responses, as described, are limited in generality to the particular stimuli employed and the impossibility, except statistically, of differentiating the ear and hemisphere variables as discrete factors influencing the evoked response.

Increased precision in application of the human scalp-recorded auditory evoked potential as an experimental or clinical technique will require further control and investigation of certain potentially critical independent variables. A review of the literature has indicated various factors which have been specifically alluded to and/or studied in association with evoked potential hemispheric asymmetries. Among these factors, included as examples are (1) attention (Ruhm, 1971, pp. 3-4); (2) electrode placementsMorrell and Salamy (1971) used right-left. central, frontal. temporo-parietal; (3) ISI-1.5 sec (Peronnet et al., 1974), $4 \mathrm{sec}$ (present study), $8 \mathrm{sec}$ (Matsumiya et al., 1972); (4) methods of measurement-frequency coherence analysis (Davis \& Wada, 1974), individual time points along the evoked potential waveform (Wood, 1975; Wood et al., 1971); (5) stimulation-binaural, dichotic, and monaural were all used by Haaland (1974); (6) number of stimuli (Ruhm, 1971, p. 5); (7) stimulus intensity (Davis \& Wada, 1974, p. 6); and (8) structure of stimuli-nonverbal human vocalizations, speech (Friedman et al., 1975), environmental noises, monosyllabic words, sentences (Matsumiya et al., 1972). The validity of evoked potentials as indicants of hemispheric specialization must inevitably result from converging experimental operations (see, for example, Wood, 1975) to determine whether EEG and neuropsychological asymmetry covary when measured concomitantly (Haaland, 1974). 


\section{REFEREN DES}

Annetr. M. The binomial distribution of right, mixed and left handed ness. Quarterly Joumal of Experimental Psychology. 1967. 19. 327-33.

Bess, J. C.. \& Ruнm, H. B. Recovery cycle of the acoustically evoked potential. Joumal of Speech and Hearing Research, 1972, 15. 507-517.

Bever. T. G., \& Chiarello, R. J. Cerebral dominance in musicians and nonmusicians. Science. 1974, 185, 537-539.

Bickford. R. Discussant of $R$. Cohn's Differential cerebral dominance to noise and verbal stimuli. Transactions of the American Neurological Association, 1971, 96, 127-131.

BROADBENT, D. E. Division of function and integration of behavior. In F. O. Schmitt \& F. G. Worden (Eds.), The neurosciences. Cambridge. Mass. London: M.I.T. Press. 1974.

Brodman, K.. Erdmann, A.. \& Wolff, H. Cornell Medical Index Health Questionnaire manual. New York: Cornell University Medical College. 1956.

Brown. W. S., Marsh, J. T.. \& Smith, J. C. Contextual meaning effects on speech-eroked potentials. Behavioral Biology. 1973. 9. 755-761.

Brugge. J. F.. Dubrowsky, N. A., Aitkin. L. M.. \& ANDERSON. D. J. Sensitivity of single neurons in auditory cortex of cat to binaural tone stimulation: effects of varying interatural time and intensity. Journal of Neurophysiology. 1969. 32. 1005-1024.

Buschbaum. M., \& Fedio. P. Visual information and evoked responses from the left and right hemispheres. Electroencephalography and Clinical Neurophysiology, 1969, 26. 266-272.

Callaway. E., \& Harris, P. R. Coupling between cortical potentials from different areas. Science, 1974, 183, 873-875.

Cons. R. Differential cerebral processing of noise and verbal stimuli. Science. 1971. 172. 599-601.

Davis. A. E.. \& W ADA. J. A. Hemispheric asymmetry: Frequency analysis of visual and auditory responses to non-verbal stimuli. Electroencephalography and Clinical Neurophysiology. 1974. 37. 1-9.

Davis, H. Classes of auditory evoked responses. Audiology'. 1973, 12. 464.469.

Davis, H.. Mast T.. Yoshie, N.. \& Zerlin. S. The slow response of the human cortex to auditory stimuli: Recovery process. Electroencephalography and Clinical Neurophysiology. 1966. 21. 105-113.

Doyi.f. J. C.. Ornstein. R.. \& Galin. D. Lateral specialization of cognitive mode: II. EEG frequency analysis. Psychophysiology. $14^{-} 4.11 .56^{-}-5,8$.

ELL'. R. The genesis of the EEG. International Review of Ne'urobiology. 1972. 15. 227-272.

Evans. E. V. Cortical representation. In O. J. Grusser \& R. Klinke (Eds.). Pattern recognition in biological and technical systems. London: Churchill, 1968.

Friedman, D., Simson, R., Ritter, W., \& Rapin. I. Cortical evoked potentials elicited by real speech words and human sounds. Electroencephulography and Clinical Neurophysiology. 1975. 38. 12-19.

Geschwind. N. Cerebral dominance and anatomic asymmetry. Ne'w England Journal of Medicine. 1972. 287. 194-195.

Geschwind. N.. \& Levitsky, W. Human brain: Left-right asymmetries in temporal speech region. Science. 1968, 161. 186-189.

Gordon. H. W. Hemispheric asymmetries in the perception of musical chords. Cortex, 1970, 6. 387-398.

HaAland, K. Y. The effect of dichotic. monaural and diotic verbal stimuli on auditory evoked potentials. Neuropsychologia. 1974. 12. 339-345.

Hall. J. L.. \& Goldstein. M. H. Representation of binaural stimuli by single units in primary auditory cortex of unanesthetized cats. Journal of the Acoustic Society of America. 1968, 43, 456-461.
Heninger. G. R., McDonald, R. K., Goff, W. R., \& Sollberger. A. Diurnal variations in the cerebral evoked response and EEG: Relations to 17-hydroxycorticosteroid levels. Archive's of Neurology, 1969, 21, 330-337.

JASPER, H. H. The ten twenty electrode system of the International Federation. Electroencephalography and Clinical Neurophy'siology'. 1958, 10, 371-375.

Keating. L. W., \& Ruhm, H. B. Within average variability of the acoustically-evoked response. Joumal of Speech and Hearing Research. 1971. 14. 179-189.

Kimura. D. Left-right differences in the perception of melodies. Quarterly Joumal of Experimental Psychology, 1964. 15. 166-171.

Kimura, D. Functional asymmetry of the brain in dichotic listening. Cortex, 1967, 3, 163-178.

Kimura, D. The asymmetry of the human brain. Scientific American. 1973, 228, 70-78.

Matsumiya. Y.. Tagliasco. V., Lombroso, C. T., \& Goodglass, H. Auditory evoked response: Meaningfulness of stimuli and interhemispheric asymmetry. Science. 1972. 175. $790-792$.

Matthews. M. V. The technology of computer music. Cambridge. Mass: M.I.T. Press. 1969.

McAdam. D. W.. \& Whittaker. H. A. Language production: Electroencephalographic localization in the normal human brain. Science, 1971, 172, 499-502.

McKee. G.. Humphrey, B., \& McAdam, D. Scaled lateralization of alpha activity during linguistic and musical tasks. Psychophy'siology: 1973, 10, 441-443.

Milner, B. Laterality effects in audition. In V. B. Monncastle (Ed.). Interhemispheric relations and cerebral dominance. Baltimore: Johns Hopkins Press. 1962.

Morrell. L. K.. \& Salamy, J. G. Hemispheric asummetry of electrocortical responses to speech stimuli. Science. 1971. 174. 164-166.

Peronnet. F.. Michel, F., Echallier, J. F.. \& Girod, J. Coronal topography of human auditory evoked responses. Electroencephalography and Clinical Neurophysiology, 1974, 37. 225-230.

Ratliffe. S. S.. \& Greenberg, H. J. The averaged encephalic response to linguistic and nonlinguistic auditory stimuli. Joumal of A uditory Research, 1972, 12, 14-25.

Rechtschaffen, A.. \& Kales, A. (Eds.), , A manual of standardized terminology, techniques and scoring system for sleep stages of human subjects. Washington, D.C: U.S. Government Printing Office. 1968.

Ruнm. H. B. Lateral speciticity of acoustically-evoked EEG responses: 1. Non-verbal. non-meaningful stimuli. Journal of Auditory Research, 1971, 11. 1-8.

Sakoda. J. M.. Cohen. B. H., \& Beall, G. Test of significance for a series of statistical tests. Psychological Bulletin. 1954. 51. $172-175$.

SIEGEL, S. Nonparametric statistics for the behavioral sciences. New York: McGraw-Hill. 1956.

Teyler. T. J.. Roemer, R. A.. Harrison, T. F., \& Thompson. R. F. Human scalp-recorded evoked-potential correlates of linguistic stimuli. Bulletin of the Psychonomic Society. 1973. 1. 333-334.

Wood. C. C. Auditory and phonetic levels of processing in speech perception: Neurophvsiological and informationprocessing analysis. Journul of Experimental Psychology. 1975. 104. 3-20.

Wood. C. C.. Goff, W. R., \& Day, R. S. Auditory evoked potentials during speech perception. Science, 1971. 173. $1248-1251$

(Received for publication April 4, 1975: revision received May 23, 1975.) 